(с) В.Ю. Мурылев 1 , ГЛ. Сорокина², Э.В. Курилина', Л.Р. Иваненко'

'ФГАОУ ВО Первый МГМУ им. И.М. Сеченова Минздрава России (Сеченовский Университет), Москва, Россия 2ГКБ им. С.П. Боткина, Москва, Россия

ЗФГКУ Главный военный клинический госпиталь им. Н.Н. Бурденко Министерства обороны России, Москва, Россия

ОБоСНОВАНИЕ: Остеоартрозом коленного сустава (гонартрозом) страдают 6\% взрослых людей. В части случаев методом выбора лечения является эндопротезирование коленного сустава. Этиология остеоартроза во многом остается неясной, но вопрос вовлечения в патологический процесс субхондральной кости не вызывает сомнений. Одной из причин, вызывающих болевой синдром после эндопротезирования коленного сустава и ведущих к асептическому расшатыванию, могут быть изменения структуры бедренной и большеберцовой костей.

ЦЕль: изучение особенностей изменений мыщелков большеберцовой кости при остеоартрозе и определение возможного влияния этих изменений на развитие нестабильности эндопротеза коленного сустава.

МЕТОДЫ: С декабря 2014 г. по февраль 2016 г. обследованы 56 пациентов, которым было выполнено эндопротезирование коленного сустава. Средний возраст пациентов составил 63 года (от 55 до 78 лет). Женщин было 52 (93\%), мужчин - 4 (7\%). Проводилось гистологическое исследование резецированных мыщелков большеберцовой кости с целью выявления костной патологии

РЕзультАТЫ: Микроскопически обнаруживались изменения, характерные для проявления остеоартроза. Во всех случаях в губчатом веществе кости обнаружена картина, характерная для остеопороза. У 15 женщин в ходе специальных методов исследования недекальцинированной кости установлена явная гистологическая картина остеомаляции.

ЗАКЛЮЧЕНИЕ: Исследование субхондральной кости у этих больных позволяет сделать Вывод, что эндопротез коленного сустава имплантируется в заведомо ослабленную кость, что может привести к неблагоприятным последствиям. Для улучшения отдаленных результатов оперативного лечения в периоперационном периоде целесообразно проведение медикаментнозной коррекции патологии костной ткани.

кЛЮчЕВЫЕ СЛОВА: Остеоартроз, эндопротезирование коленного сустава, субхондральный, остеопороз, остеомаляция;

\title{
SUBCHONDRAL BONE CONDITION AND TOTAL KNEE ARTHROPLASTY IN PATIENTS WITH KNEE OSTEOARTHRITIS
}

(c) V.Y. Murylev', G.L. Sorokina², E.V. Kurilina', L.R. Ivanenko'

II.M.Sechenov First Moscow State Medical University, Moscow, Russia

2S.P.Botkin City Hospital, Moscow, Russia

${ }^{3}$ N.I.Burdenko Main Military Clinical Hospital, Moscow, Russia

BACKGROUND: $6 \%$ of adults suffer from knee joint osteoarthritis. In some cases, the method of choice of treatment is knee arthroplasty. The etiology of osteoarthritis remains largely unclear, but the question of involving the subchondral bone in the pathological process is beyond doubt. One of the causes of pain and other adverse effects after knee replacement may be subchondral bone pathology of the femur and tibia.

AIMS: To study the changes in the condyles of the tibia in osteoarthritis and to determine the possible impact of these changes on the development of instability of the knee joint endoprosthesis.

METHODS: From December 2014 to February 2016, 56 patients were examined. They underwent total arthroplasty of the knee joint. The average age of the patients was 63 years (from 55 to 78 years). Women were 52 (93\%), men - 4 (7\%). A histological examination of the resected tibial condyles was carried out to reveal bone pathology.

RESULTS: Typical changes for osteoarthritis were found microscopically. In all cases the signs of osteoporosis were present. A clear histological picture of osteomalacia in the non-calcinated bone was found in 15 women.

CONCLUSIONS: Having studied the subchondral bone in these patients we can conclude that the knee endoprosthesis is implanted into a weakened bone, which can lead to adverse effects. To improve the long-term results of surgical treatment, medical correction of bone tissue pathology in the perioperative period is suggested.

KEYWORDS: Osteoarthritis, knee arthroplasty, subchondral, osteoporosis, osteomalacia; 


\section{ВВЕДЕНИЕ}

Самой распространенной формой поражения суставов и одной из основных причин нетрудоспособности является остеоартроз $[1,2]$. Большинство больных - пожилые люди и женщины в постменопаузе, находящиеся также в группе риска развития остеопороза и остеомаляции. По тяжести нарушений функции опорно-двигательного аппарата одно из ведущих мест занимает поражение коленного сустава [3]. Остеоартрозом коленного сустава (гонартрозом) страдают 6\% взрослых людей $[4,5]$ В части случаев методом выбора лечения является эндопротезирование коленного сустава.

Этиология остеоартроза во многом остается неясной, но вопрос вовлечения в патологический процесс субхондральной кости не вызывает сомнений. В связи с тем, что изменения субхондральной кости сохраняются и прогрессируют также после оперативного вмешательства, когда функцию резецированного суставного хряща выполняют искусственные компоненты эндопротеза, фиксированные к кости посредством костного цемента либо по технологии pressfit с возможностью остеоинтеграции, расшифровка морфологических изменений может быть важным шагом в коррекции этих нарушений.

По статистике, 82-89\% больных остаются довольны результатом эндопротезирования [6]. У остальных пациентов остаются жалобы, чаще всего на боли, для которых характерны полиморфность и полиэтиологичность. Одной из причин, вызывающих болевой синдром и ведущих к асептическому расшатыванию, могут быть изменения структуры бедренной и большеберцовой костей.

Целью нашей работы было изучение особенностей изменений мыщелков большеберцовой кости при остеоартрозе и определение возможного влияния этих изменений на развитие нестабильности эндопротеза коленного сустава.

\section{Изменения хряща и субхондральной кости при} гонартрозе

Приспособление кости к механической нагрузке регулируется путем постоянной резорбции и образования кости. В литературе приводятся противоречивые данные о влиянии гонартроза на субхондральную кость. D. Bobinak и соавт. [7] отметили увеличение в объеме костной доли и толщины трабекул под тибиальным плато с разрушенным хрящом. C. Lindsey и соавт. обнаружили уплотнение кости под поврежденным хрящом медиального мыщелка большеберцовой кости и остеопороз в латеральном мыщелке. Напротив, V. Patel и соавт. [9] обнаружили, что в костно-хрящевых препаратах большеберцовой кости при остеоартрозе уменьшаются костный объем и толщина трабекул плато. Проявление признаков остеопороза в субхондральной кости можно объяснить дегенерацией вышележащего хряща, склеротические изменения - результатом изменившихся нагрузок на суставную поверхность. В действительности оба эффекта могут возникать одновременно в суставе, пораженном остеоартрозом.

На границе хряща и субхондральной кости имеется своеобразный участок - базофильная или пограничная линия - tidemark (по Гонгадзе Л.Р.) (рис. 3-5). Согласно данным Л.Р. Гонгадзе [10] и В.Н. Павловой и соавт. [11], пограничная линия суставного хряща взрослого человека содержит в высоких концентрациях, по сравнению с соседними участками матрикса, сложный набор таких компонентов, как белки, фосфолипиды, гликозаминогликаны, ферменты. Это не мембранная структура, а морфологически и гистохимически обособленный слой матрикса, который формируется на последних этапах энхондрального окостенения, изменяется, но не исчезает с возрастом. Он обеспечивает селективное проникновение веществ из кости в хрящ, имеет непосредственное отношение к транспорту воды, электролитов, продуктов метаболизма и солей кальция. Результаты исследований [10, 12] позволяют утверждать, что базофильная линия предотвращает кальцификацию суставного хряща. Зона первичной кальцификации является промежуточным звеном между суставным хрящом и эпифизом. Кроме того, обызвествленный хрящ скрепляет весь суставной хрящ с субхондральной костью. Линия tidemark является самой прочной зоной проксимального отдела большеберцовой кости. От состояния этой линии зависит резистентность мыщелков большеберцовой кости к нагрузкам [10].

\section{Изменения проксимального отдела большеберцовой}

кости после имплантации эндопротеза

Следует отметить, что при имплантации тибиального компонента эндопротеза коленного сустава осуществляется резекция мыщелков большеберцовой кости на глубину в среднем 6-10 мм, что означает резекцию линии tidemark, которая является самой прочной зоной в этом отделе.

В 1-е сутки после имплантации эндопротеза по ходу киля тибиального компонента в костной ткани образуется канал, стенки которого покрыты тонким слоем свернувшейся крови и мелкими костными осколками. В костном мозге по краю канала возникают мелкие кровоизлияния. Позднее вокруг имплантата образуется соединительнотканная, а затем костная капсула с соединительнотканной прослойкой между костью и имплантатом.

После эндопротезирования и начала пользования конечностью ремоделирование кости осуществляется таким образом, что костные балки формируются с использованием частей имплантата как опорной структуры. Стенки канала, образованного килем тибиального компонента, приобретают разную толщину: в дистальном отделе, на который приходится наибольшая нагрузка, отмечены наибольшие толщина и количество костных балок. Последние, по мере приближения к плато, становятся тоньше, количество их уменьшается. Полная перестройка губчатой костной ткани происходит медленно. По данным Т.К. Осипенковой-Вичтомовой, даже через 4 года в области повреждения кости можно обнаружить островки грубоволокнистых костных структур, остатки провизорной мозоли [13]. В ряде случаев возникает так называемое асептическое расшатывание эндопротеза коленного сустава, в развитии которого основополагающую роль играет состояние субхондральной кости.

\section{МЕТОДЫ}

С декабря 2014 г. по февраль 2016 г. обследованы 56 пациентов, которым было выполнено эндопротезирование коленного сустава. Средний возраст пациентов составил 63 года (от 55 до 78 лет). Женщин было 52 (93 \%), мужчин $4(7 \%)$. 


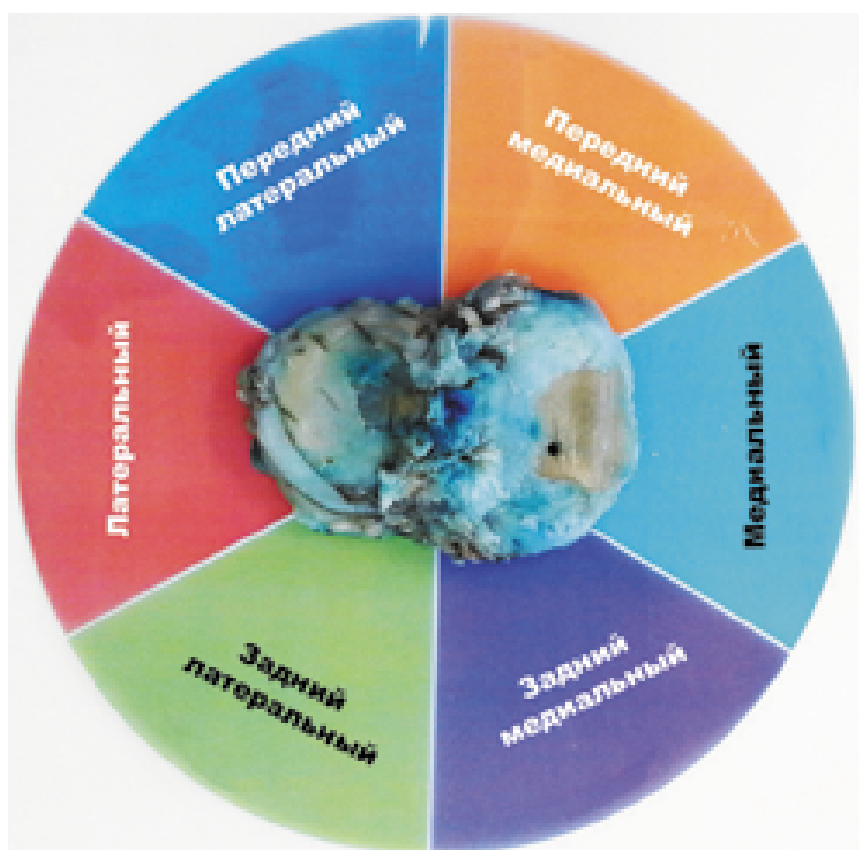

Рис. 1. Разделение мыщелков большеберцовой кости на сегменты

Всем пациентам перед операцией эндопротезирования проводилась денситометрия. Среднее значение Т-критерия по шейке бедра составило -1,3 (от -2,1 до 0,5).

До операции произведена оценка функции коленных суставов по шкале KOOS (Knee Injury and Osteoarthritis Outcome Score).

Мыщелки большеберцовой кости, резецированные во время операции и включающие хрящ и субхондральную кость, были направлены на гистологическое исследование. Размер полученных препаратов составлял от 40×55 до 55×70 мм, а наибольшая толщина - от 6 до 12 мм. С целью удобства обработки и исследования полученный спил условно разделялся на сегменты: латеральный, медиальный, переднелатеральный, переднемедиальный, заднелатеральный и заднемедиальный (рис. 1).

В ходе приготовления гистологических препаратов принцип посегментного исследования сохранялся, что позволило детально исследовать на сагиттальных срезах структуры хряща и субхондральной зоны от периферии к центру и снаружи внутрь. Цельные костные препараты подвергались декальцинации и сегментировались. Каждый сегмент в зависимости от степени деструктивных изменений делили еще на 3-4 костные пластины и приготавливали гистологические срезы с них. Материал окрашивали гематоксилином, эозином. Часть препаратов не подвергалась декальцинации и была окрашена по Массону. Препараты исследовали под микроскопом Carl Zeiss Axio при 10, 20 и 50 кратном увеличении. Препараты описывали и производили фотофиксацию.

\section{РЕЗУЛЬТАТЫ И ОБСУЖДЕНИЕ}

В ходе макроскопического исследования обращала на себя внимание хорошо видимая глазом атрофия гиалинового хряща с деструкцией в различных зонах. Во всех случаях поверхность хряща была тусклой, желтовато-серой, шероховатой, зернистой. Толщина суставного хряща колебалась от 0,1 до 0,4 см. В 38 случаях на отдельных участках он был сильно истончен, но сохранен на протяжении. В 18 случаях визуализировались зоны, где хрящ был

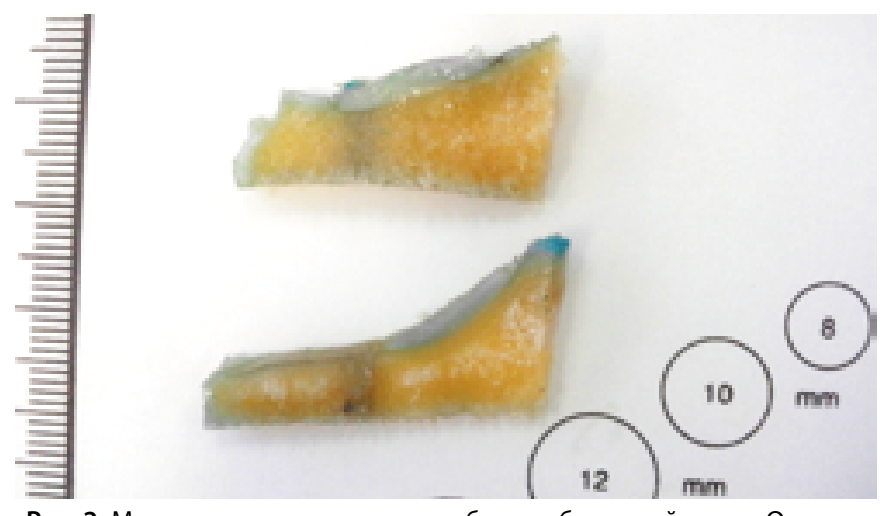

Рис. 2. Макропрепараты мыщелков большеберцовой кости. Отмечаются истончение и в некоторых зонах - отсутствие суставного хряща.

слущен, узурирован вплоть до оголения костного шлифа (рис. 2).

Проведенный анализ показал, что наибольшей дегенерации (47 случаев) подвергались внутренние мыщелки, в основном медиальный и переднемедиальный сегменты, причем истончение хряща и его десквамация распространялись вплоть до наружного края кортикальной зоны. В 9 случаях дегенеративные изменения были наиболее выражены в области наружных мыщелков, в заднелатеральных и латеральных сегментах, где также наблюдались явления истончения и дефекты хрящевой поверхности, однако полной деструкции хрящевой массы с оголением подлежащей кости не установлено. В соответствии с системой оценки гистопатологических изменений суставного гиалинового хряща, предложенной OARSI (Международное общество по изучению остеоартроза), описанные изменения соответствовали III-IV стадии, а в отдельных случаях $\checkmark$ стадии патологических изменений. Микроскопически обнаруживались изменения, характерные для проявления остеоартроза (рис. 3).

Поверхностный слой хряща практически на всем протяжении лишен бесклеточной пластины, целостность суставной поверхности нарушена, отмечалось наличие горизонтальных разволокнений и трещин, основное вещество обеднено хрящевыми клетками, линия tidemark крупнозубчатого вида. В 10 (17,9\%) случаях отмечалось отслоение минерализованного хряща от субхондральной кости, что, по-видимому, обусловлено возрастной дегенерацией (возраст больных в этой группе превышал 70 лет).

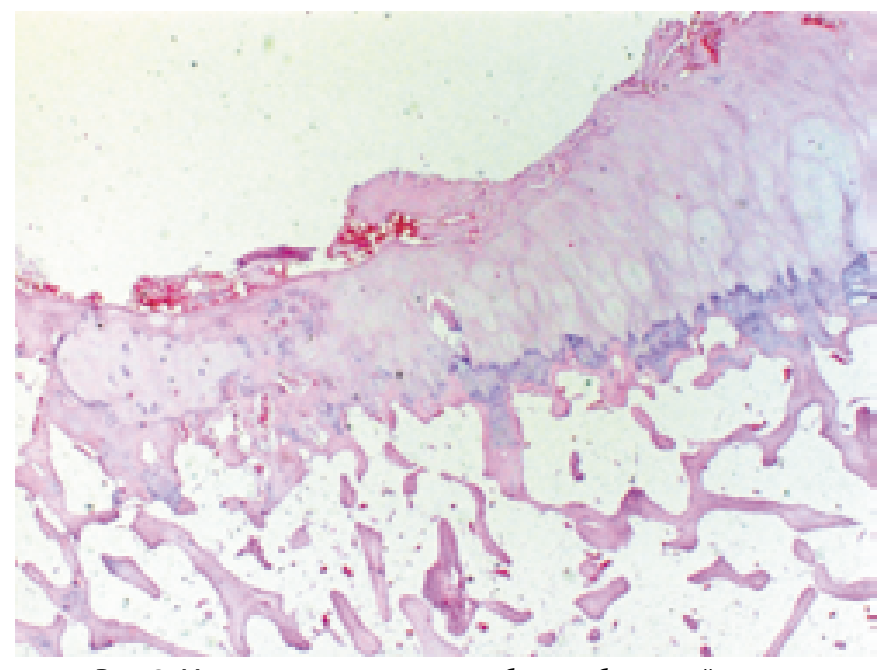

Рис. 3. Микропрепарат мыщелка большеберцовой кости. Гематоксилин-эозин (увеличение $\times 20$ ). 


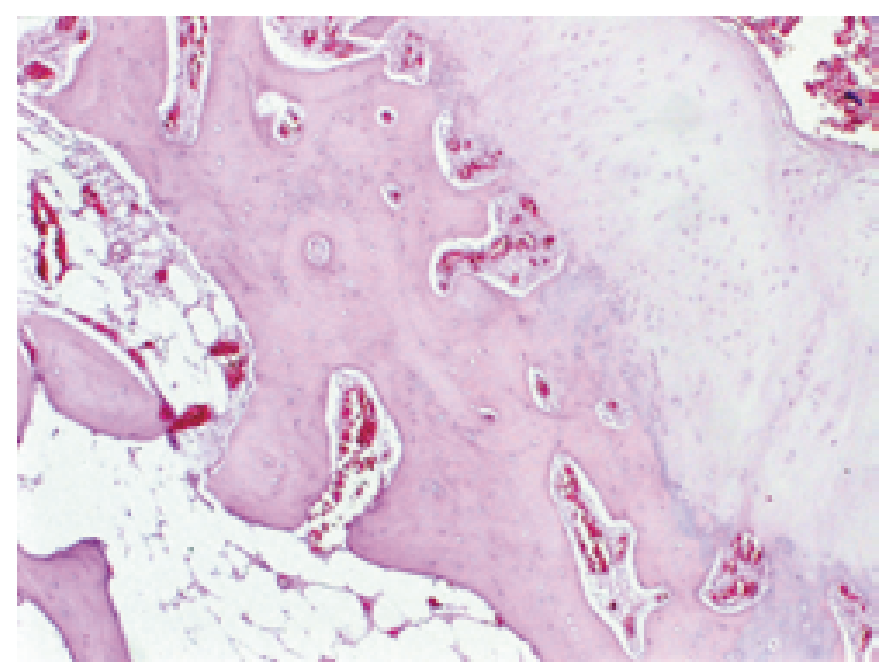

Рис. 4. Прерывистость линии tidemark. Разрастание грануляционной ткани Гематоксилин-эозин (увеличение ×20).

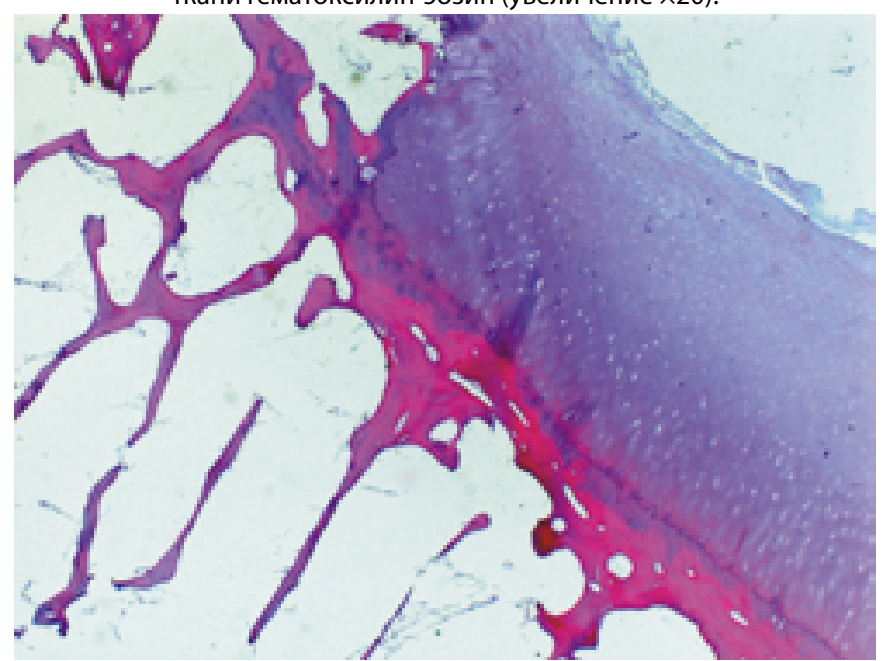

Рис. 5. Гистологическая картина остеопороза. Гематоксилин-эозин (увеличение $\times 20$ ).

В 7 (12,5\%) случаях отмечались истончение и прерывистость линии tidemark вплоть до ее полного отсутствия. При этом на поверхности субхондральной кости отмечалось разрастание грануляционной ткани. Данные изменения являются следствием значительного износа хряща и постепенного замещения его фиброзной тканью (рис. 4).

Во всех случаях в губчатом веществе кости обнаружена картина, характерная для остеопороза. Межбалочное пространство заполнено жировой тканью, встречаются отдельные мелкие сосуды, большей частью запустевшие, с измененной стенкой (рис. 5).

Следует отметить, что локальный остеопороз субхондральной кости выявлялся у всех пациентов, включая имеющих нормальные показатели денситометрии.

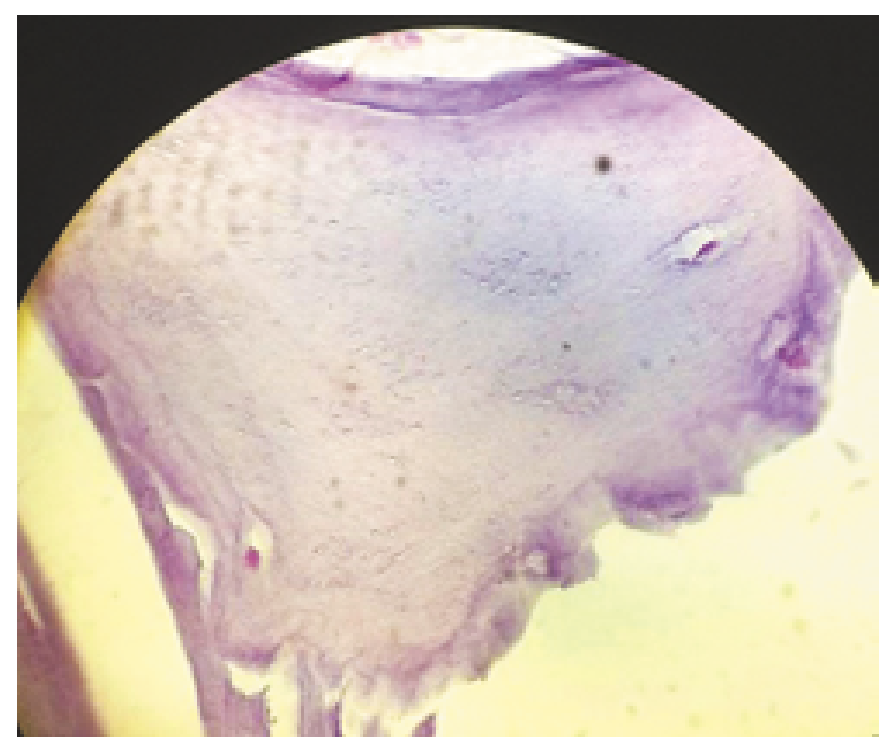

Рис. 6. Гистологическая картина остеомаляции. Гематоксилин-эозин (увеличение $\times 40$ ).

В ходе специальных методов исследования недекальцинированной кости у 15 женщин в отдельных полях зрения на поверхности минерализованных костных балок отмечалось наложение гомогенной неминерализованной массы, расцененной нами как остеоид (рис. 6), являющийся главным маркером остеомаляции. Также у этой группы больных перед операцией был проведен анализ биохимических показателей крови (таб. 1).

По принятой в клинике методике, все больные через 3 месяца после операции были осмотрены лечащими врачами и им рекомендована остеотропная терапия с учетом данных клинического и гистологического исследований. Через год производилось повторное обследование и оценка по шкале KOOS. У всех больных купирован болевой синдром, объём движений восстановлен. По клиническим и рентгенологическим данным интеграция импланта удовлетворительная.

Как видно из табл. 1 у всех пациентов наблюдался дефицит или недостаточность витамина D, что в ряде случаев сопровождалось повышением активности щелочной фосфатазы в крови

\section{ЗАКЛЮЧЕНИЕ}

Гистологическое исследование мыщелков большеберцовой кости у 56 больных, кроме картины выраженного остеоартроза, по поводу которого выполнялось эндопротезирование коленного сустава, показало и другие изменения хряща и субхондральной кости. Так, в губчатом веществе кости у большинства пациентов отмечен остео-

Таблица 1. Биохимические показатели крови пациентов

\begin{tabular}{lcccc}
\hline \multicolumn{1}{c}{ Показатель } & \multicolumn{2}{c}{ Значение } & среднее & норма \\
Креатинин, ммоль/л & минимальное & максимальное & 85,44 & 44-110 \\
Кальций, ммоль/л & 68 & 114 & 2,47 & $2,15-2,50$ \\
Фосфор, ммоль/л & 2,04 & 3,08 & 1,33 & $0,64-1,29$ \\
Щелочная фосфатаза, МЕ/л & 1,27 & 1,39 & 86,3 & $30-120$ \\
$25(О Н)$ витамин D общий, нг/мл & 48 & 139 & 13,8 & $>30$ \\
\hline
\end{tabular}


пороз, который проявлялся истончением и уменьшением количества костных балок. У 15 женщин установлена явная гистологическая картина остеомаляции.

Следует отметить, что после эндопротезирования коленного сустава именно такая измененная кость является опорой под тибиальным компонентом эндопротеза. Костный цемент в данной ситуации может армировать порозную кость, однако он же может вызвать и прогрессирующий лизис кости. Кроме того, сама технология эндопротезирования коленного сустава подразумевает резекцию наиболее прочной зоны проксимального отдела большеберцовой кости - так называемой линии tidemark. Это можно рассматривать, как факторы отрицательного влияния на результаты эндопротезирования коленного сустава.

В связи с наличием изменений субхондральной кости, на которую в дальнейшем падает увеличенная нагрузка, необходимо назначение остеотропной терапии, включая препараты витамина D, всем больным до и после тотального эндопротезирования коленного сустава.

\section{ДОПОЛНИТЕЛЬНАЯ ИНФОРМАЦИЯ.}

Информация о конфликте интересов. Авторы декларируют отсутствие явных и потенциальных конфликтов интересов, связанных с публикацией настоящей статьи.

Информация о финансировании. Исследование проведено только за счет личных средств авторского коллектива.

Соответствие нормам этики. От всех людей, ставших объектами исследования, получено добровольное информированное согласие на участие.

Участие авторов: Мурылев В.Ю. - концепция и дизайн исследования; Сорокина ГЛ. - идея исследования, сбор и анализ полученных данных, написание текста; Курилина Э.В. - гистологическое исследование препаратов; Иваненко Л.Р. - анализ полученных данных, написание текста, оформление иллюстраций.

\section{СПИСОК ЛИТЕРАТУРЫ | REFERENCES}

1. Peyron JG. Osteoarthritis. The epidemiologic viewpoint. Clinical orthopaedics and related research. 1986;213:13-19.

2. Felson DT. Epidemiology of hip and knee osteoarthritis. Epidemiologic reviews. 1988;10:1-28.

3. Берглезов М.А., Угнивенко В.И., Надгериев В.М., и др. Комплексное лечение больных с тяжелыми нарушениями функции нижних конечностей в амбулаторных условиях. Пособие для врачей. М.: ЦИТО; 1999. [Berglezov MA, Ugnivenko VI, Nadgeriev VM, et al. Kompleksnoe lechenie bol'nykh s tyazhelymi narusheniyami funktsii nizhnikh konechnostey v ambulatornykh usloviyakh. Posobie dlya vrachey. Moscow: CITO; 1999. (In Russ.)]

4. Felson DT, Couropmitree NN, Chaisson CE, et al. Evidence for a Mendelian gene in a segregation analysis of generalized radiographic osteoarthritis: The Framingham study. Arthritis \& Rheumatism 1998:41(6):1064-1071. doi: 10.1002/1529-0131(199806)41:6<1064::aid-art13>3.0.co;2-k.

5. Andrianakos AA, Kontelis LK, Karamitsos DG, et al. Prevalence of symptomatic knee, hand, and hip osteoarthritis in Greece: the ESORDIG study. The Journal of rheumatology 2006;33:2507-2513.

6. Bourne RB, Chesworth BM, Davis AM, et al. Patient Satisfaction after Total Knee Arthroplasty: Who is Satisfied and Who is Not? Clinical Orthopaedics and Related Research. 2009:468(1):57-63. doi: 10.1007/s1 1999-009-1119-9

7. Bobinac D, Spanjol J, Zoricic S, Maric I. Changes in articular cartilage and subchondral bone histomorphometry in os- teoarthritic knee joints in humans. Bone. 2003:32(3):284-290. doi: 10.1016/s8756-3282(02)00982-1

8. Lindsey CT, Narasimhan A, Adolfo JM, et al. Magnetic resonance evaluation of the interrelationship between articular cartilage and trabecular bone of the osteoarthritic knee11This work is supported by NIH grant RO1 AR 46905 \& AG 17762. Osteoarthritis Cartilage. 2004;12(2):86-96. doi: 10.1016/j.joca.2003.10.009

9. Patel V, Issever AS, Burghardt A, et al. MicroCT evaluation of normal and osteoarthritic bone structure in human knee specimens. J Orth Res. 2003;21 (1):6-13. doi: 10.1016/s0736-0266(02)00093-1

10. Гонгадзе Л. Р. Базофильная линия суставного хряща в норме и при некоторых патологических состояниях // Архив анатомии. - 1987. - №. 4. - C. 52. [Gongadze LR. Bazofil'naya liniya sustavnogo khryashcha v norme i pri nekotorykh patologicheskikh sostoyaniyakh. Arkhiv anatomii. 1987;4:52. (In Russ.)]

11. Павлова В.Н, Копьева Т.Н, Слуцкий Л.И., Павлов Г.Г. Хрящ. — М.: Медицина; 1988. [Pavlova VN, Kop'eva TN, Slutskiy LI., Pavlov GG. Khryashch. Moscow: Medicina; 1988. (In Russ.)]

12. Слесаренко Н. А. Метаболические свойства суставного хряща // Ортопедия, травматология и протезирование. - 1994. - № . 4. - С. 90. [Slesarenko NA. Metabolicheskie svoystva sustavnogo khryashcha. Orthopaedics, Traumatology And Prosthetics. 1994;4:90 p. (In Russ.)]

13. Осипенкова-Вичтомова Т.К. Гистоморфологическая экспертиза костей. - М.: Медицина, 2009. [Osipenkova-Vichtomova TK. Gistomorfologicheskaya ekspertiza kostey. Moscow: Medicina; 2009. (In Russ.)]

\section{ИНФОРМАЦИЯ ОБ АВТОРАХ [AUTHORS INFO]}

Сорокина Галина Леонидовна, врач траматолог-ортопед [Galina L. Sorokina, MD], адрес: 125284, Москва, 2-й Боткинский пр-д, 5 [address: Moscow, Second Botkinsky st., 5, 125284].

Мурылев Валерий Юрьевич, д.м.Н., профессор кафедры травматологии, ортопедии и хирургии катастроф лечебного факультета, заведующий Московским городским центром эндопротезирования костей и суставов [Valeriy U. Murylyov, MD, PhD, professor); eLibrary SPIN: 7695-1145. Kyрилина Элла Владимировна, заведующая патологоанатомическим отделением [Ella V. Kurilina, MD]. Иваненко Леонид Радиславович, клинический ординатор кафедры травматологии, ортопедии и хирургии катастроф [Leonid R. Ivanenko, MD resident].

\section{ЦИТИРОВАТЬ:}

Мурылев В.Ю., Сорокина ГЛ., Курилина Э.В., Иваненко Л.Р. Состояние субхондральной кости при гонартрозе и эндопротезирование коленного сустава. // Остеопороз и остеопатии. — 2017. — Т. 20. — №1. — C.12-16. doi: 10.14341/osteo2017112-16

\section{TO CITE THIS ARTICLE:}

Murylev VY, Sorokina GL, Kurilina EV, Ivanenko LR. Subchondral bone condition and total knee arthroplasty in patients with knee osteoarthritis. Osteoporosis and bone diseases. 2017;20(1):12-16. doi: 10.14341/osteo2017112-16 